\title{
Diversidade de Phasmida (Insecta) na Serra do Espinhaço, Chapada Diamantina (MG)
}

\author{
Fernanda Figueiredo de Araujo \& André Rinaldo Senna Garraffoni
}

\begin{abstract}
Universidade Federal dos Vales do Jequitinhonha e Mucuri - Departamento de Ciências Biológicas - FCBS, e-mail: figueiredofaraujo@gmail.com, garraffoni@gmail.com (Autor para correspondência ${ }^{\varpi}$ )
\end{abstract}

\author{
EntomoBrasilis 5 (2): 137-145 (2012)
}

\begin{abstract}
Resumo. Os representantes da ordem Phasmatodea são conhecidos popularmente como bicho-pau e bicho-folha pela grande capacidade de camuflagem. Atualmente são conhecidas aproximadamente 3000 espécies válidas em todo o mundo, agrupadas em 523 gêneros e 13 famílias. A fauna de fasmídeos brasileiros apresenta mais de 200 espécies, porém um grande número de espécies apresenta problemas taxonômicos. O presente estudo relata os achados do levantamento das espécies de Phasmatodea em quatro pontos amostrais próximos ao município de Diamantina-MG, localizados no planalto Diamantina, Cadeia do Espinhaço. Foram realizadas coletas na mata ciliar do córrego Soberbo, Caminho dos Escravos, Parque Estadual do Biribiri e Parque Nacional das Sempre Vivas, no período de outubro de 2009 a março de 2011, abrangendo as estações chuvosa e seca. Foram coletados um total de 47 indivíduos, sendo 20 fêmeas, 17 machos e 10 ninfas pertencentes à família Heteronemiidae, com dois gêneros Heteronemia e Paraleptynia, e a família Pseudophasmatidae com o gênero Paraphasma, sendo todos os espécimes coletados durante o período chuvoso. Além disso, uma chave de identificação para todos os fasmídeos identificados para o Estado de Minas é também fornecido.
\end{abstract}

Palavras-chave: Chave de identificação; Fasmídeos; Sistemática; Taxonomia.

\section{Phasmatodea (Insecta) from Espinhaço Range, Chapada Diamantina Plateau (MG)}

Abstract. The specimens of the Order Phasmatodea are popular know as Stick insects or leaf insect characterized by a remarkable similarity to their host vegetation. Currently, more than 3000 species are considered valid in the world, grouped in 523 genera and 13 families. The Brazilian phasmid fauna has more than 200 species described, but most of than show taxonomical problems. The present communication is a taxonomic survey of the phasmids fauna found in the municipality of Diamantina-MG, Chapada Diamantina plateau, Espinhaço range. Samplings were done in the forest gallery of Soberbo Stream, Biribiri State Park and Sempre-Vivas National Park, during the dry and wet seasons, between October 2009 to march 2010. A total of 47 specimens have been examined, 20 female, 17 male and 10 nymphs belonging to the family Heteronemiidae, with 2 genera Heteronemia and Paraleptynia, and the family Pseudophasmatidae with the genus Paraphasma were collected only in the wet period. Furthermore, an identification key for all phasmids genera identified from Minas Gerais State is also provided.

Keywords: Identification key; Phasmids; Systematic; Taxonomy.

A ordem Phasmatodea (do grego phasma, fantasma, aparição) é representada por insetos terrestres, noturnos, fitófagos e de movimentos muito lentos que vivem sobre folhas, troncos, arbustos e são encontrados principalmente em ecossistemas tropicais e temperados (BEDFORD 1978; CONLE \& Hennemann 2011). No Brasil, são popularmente conhecidos como bicho-pau ou bicho-folha por apresentarem coloração críptica, se camuflando entre os galhos secos ou folha de uma planta.

Os organismos desse táxon possuem corpo alongado com cabeça prognata e antenas filiformes, geralmente longas com oito a cem flagelômeros. Os fasmídeos são grandes quando comparados a indivíduos de outras ordens de insetos, podendo apresentar um comprimento que vária entre 1-35 cm, porém há registros de fasmídeos com mais $50 \mathrm{~cm}$ de comprimento (Costa Lima 1938), sendo considerados desta forma os mais longos insetos que se tem registro. $\mathrm{O}$ corpo desses insetos é dividido em cabeça, tórax e abdômen geralmente cilíndrico. As asas podem estar ausentes ou presentes. As pernas são alongadas (não saltatórias), podendo conter dentes ou saliências foliáceas que contribuem para o aumento da semelhança destes insetos com folhas e galhos (Costa Lima 1938). Os primeiros registros fósseis de fasmídeos datam, provavelmente, da Era Cenozóica (NeL et al. 2004), com aproximadamente 65 milhões de anos.
A ordem Phasmatodea é atualmente dividida em duas subordens: Timematodea e Euphasmatodea (Conle \& Hennemann 2011). A grande diferença morfológica entre os dois grupo é o número de artículos tarsais, já que os espécimes de Timematodea apresentam três e todos os demais fasmídeos contêm cinco (Tilgner 2002). A subordem Timematodea é composta apenas pelo gênero Timema, de ocorrência restrita aos Estados Unidos. Já Euphasmatodea possui dois grandes grupos: Areolatae e Anareolatae. Os espécimes representantes de Areolatae possuem como sinapomorfia uma região aprofundada de forma geralmente triangular e aspecto membranoso, localizada no lado interno da tíbia, denominada área apical, sendo a principal diferença entre os dois grupos.

Os representantes da ordem Phasmatodea possuem um acentuado dimorfismo sexual: os machos são menores que as fêmeas e, se em uma espécie haver um dos sexos alados, este será sempre o macho. As fêmeas apresentam placa subgenital bastante alongada, formando um ovipositor, que pode ser usado na sexagem dos espécimes (BROCK \& HASENPUSH 2009), embora em algumas espécies a placa subgenital alongada também possa estar presente nos machos, sendo necessário análises da morfologia interna do aparelho reprodutor para a indicação do sexo. A reprodução é tipicamente sexuada, porém a partenogênese pode ocorrer frequentemente (BEDFORD 1978). 
No total são conhecidas aproximadamente 3000 espécies registradas em todo o mundo, agrupadas em 523 gêneros e 13 famílias (ZOMPRo 2004; OTTE \& BROCK 2005), destas, cerca de 800 espécies foram descritas para a região Neotropical. Já no Brasil foram registradas mais de 200 espécies (Zompro \& DoMENico 2005) e atendo-se a Minas Gerais foram descritas somente duas espécies, sendo elas Otocraniella flagelloantennata Zompro, 2004 com local tipo em Chapéu do Sol, Serra do Cipó e Cladomorphus trimariensis Kumagai \& Fonseca, 2009 coletados originalmente em Três Marias. Contudo, é importante ressaltar que o número de espécies registrados no Brasil pode estar muito longe da realizada, uma vez que os problemas taxonômicos do táxon no país são graves.

Poucas coletas foram feitas na América do Sul e, ainda assim, possui o segundo maior número de espécies descritas (por volta de 600), abaixo somente da Indomalásia, onde foram realizadas coletas intensivas no leste da Ásia (Отте \& BRоск 2005).

O objetivo do presente trabalho foi realizar um levantamento das espécies de Phasmatodea que ocorrem em diferentes áreas próximas ao município de Diamantina- MG, Planalto Diamantina, bem como ampliar o conhecimento da sistemática e distribuição dos fasmídeos. Tal trabalho poderá subsidiar futuros trabalhos sobre ecologia, biologia e biogeografia dos fasmídeos, bem como melhorar o conhecimento taxonômico do grupo para o estado de Minas Gerais e, consequentemente no Brasil. Por último, foi confeccionada uma chave dicotômica para os gêneros de Phasmatodea encontrados no Estado de Minas Gerais.

\section{MATERIAL E MÉTODOS}

Área de Estudo. A Cadeia do Espinhaço envolve um conjunto de serras que se estende do Estado de Minas Gerais à Bahia, com cerca de $1.000 \mathrm{~km}$ de extensão, possuindo um relevo marcadamente acidentado com altitudes superiores a $1.000 \mathrm{~m}$ acima do nível do mar, alcançando um máximo de $2.014 \mathrm{~m}$ de altitude no Pico do Itambé, localizado a cerca de $30 \mathrm{~km}$ a sudeste de Diamantina- MG (Almeida-Abreu et al. 2005). Em Minas Gerais a Serra do Espinhaço estende-se por cerca de $550 \mathrm{~km}$, com direção N-S (AzEvEDo et al. 2008).

A porção Meridional da Cadeia do Espinhaço, ou Serra do Espinhaço Meridional, tem início na Serra do Cipó, em sua extremidade sul, onde a largura é reduzida, com cerca de 30 $\mathrm{km}$ aumentando em direção ao norte, atingindo cerca de $90 \mathrm{~km}$ entre Santo Antônio do Itambé e Conselheiro Mata. A serra do Espinhaço Meridional abrange municípios de três macrorregiões de Minas Gerais, sendo elas a Jequitinhonha, Rio Doce e Campos das Vertentes, atuando como importante divisor de águas das bacias hidrográficas do Rio São Francisco, em sua borda leste,
Jequitinhonha, no Planalto de Diamantina e Rio Doce e Araçuaí, na borda leste (AlmeidA-Abreu et al. 2005).

A região do Planalto Diamantina constitui um dos domínios orográficos da porção meridional da Cadeia do Espinhaço, sendo a área mais elevada, com altitude média em torno de $1300 \mathrm{~m}$ (Almeida-Abreu et al. 2005; Drummond et al. 2005; Azevedo et al. 2008).

As coletas foram realizadas no Planalto de Diamantina, às margens do Córrego Soberbo Campus JK- UFVJM (18 $11.796^{\prime} \mathrm{S}$ e $43^{\circ}$ 34.054'O; Alt. 1325m), Caminho dos Escravos ( $18^{\circ} 13.26^{\prime} \mathrm{S}$ e $43^{\circ}$ 35.74'O; Alt. 1370), Parque Estadual do Biribiri ( $18^{\circ} 06.24^{\prime} \mathrm{S}$ e $43^{\circ} 32.26$ 'O; Alt. $723 \mathrm{~m}$ ) e área próxima ao Parque Nacional das Sempre Vivas - PNSV $\left(17^{\circ} 53.35^{\prime}\right.$ S e $43^{\circ} 35.658^{\prime} \mathrm{O}$; Alt. $\left.743 \mathrm{~m}\right)$ (Figura 1). A vegetação presente em todas as áreas de coleta é bem característica do bioma cerrado, com fitofisionomias dos campos rupestres (AlmEIDA-ABREU et al. 2005), sendo rasteira ou de pequeno a médio porte.

Amostragem. As coletas foram realizadas no período de outubro de 2009 a janeiro de 2011, abrangendo as estações chuvosa e seca. A estação chuvosa compreendeu os meses de outubro de 2009 a março de 2010 e outubro de 2010 a março de 2011, enquanto que a estação seca os de abril a julho de 2010. Durante a estação chuvosa as coletas foram realizadas na mata ciliar do Córrego Soberbo, Caminho dos Escravos e Parque Estadual do Biribiri, enquanto que no decorrer da estação seca estas foram realizadas na mata Ciliar do Córrego Soberbo e em área próxima ao Parque Nacional das Sempre Vivas (Figuras 1). As coletas foram feitas com maior frequência na estação chuvosa, refletindo assim um maior esforço amostral nesse período.

Por tratar-se de animais de hábito noturno e grande capacidade de camuflagem, as coletas foram realizadas manualmente com auxilio de lanternas e sacos plásticos para armazenar os espécimes, das 20 às 23 horas.

Após coletados, os animais foram levados para o Laboratório de Zoologia da Universidade Federal dos Vales do Jequitinhonha e Mucuri (UFVJM), onde foram sacrificados em câmara letal com cianeto de potássio e analisados sob microscópio esteroscópico. Os indivíduos coletados foram depositados na coleção do próprio Laboratório de Zoologia da UFVJM.

Identificação dos Espécimes. A identificação dos espécimes coletados ocorreu com base em bibliografias especializadas e catálogo eletrônico das espécies de Phasmatodea do mundo (BROCK et al. 2011).

\section{RESULTADOS E DISCUSSÃO}

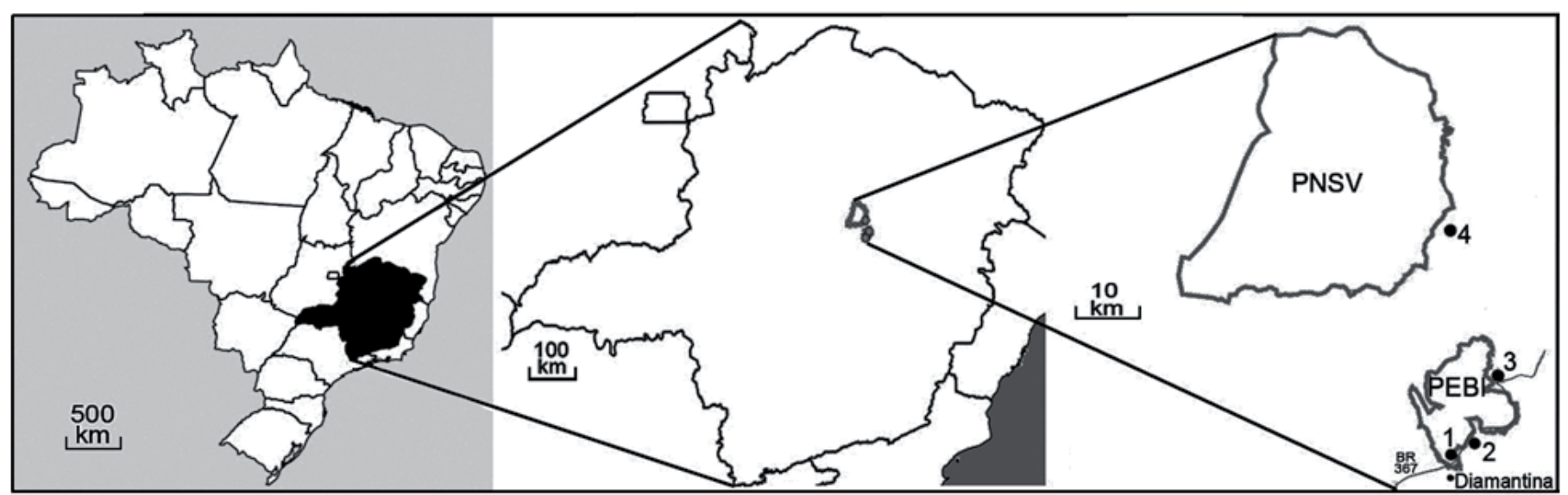

Figura 1: Mapa ilustrando os locais de amostragem. Siglas: PNSV-Parque Nacional das Sempre Vivas, PEBI- Parque Estadual do Biribiri, 1- Ponto Caminho dos Escravos, 2- Ponto Córrego Soberbo Campus JK- UFVJM, 3- Ponto Parque Estadual do Biribiri, 4- Ponto próxima ao Parque Nacional das Sempre Vivas. 
Foram coletados 47 espécimes, sendo 20 fêmeas, 17 machos e 10 ninfas com estágios e sexo indeterminados, identificados como pertencentes a três gêneros e duas famílias.

A maioria dos indivíduos foram identificados como pertencentes à família Heteronemiidae Rehn, 1904, com dois gêneros, Heteronemia Gray, 1835 e Paraleptynia Caudell, 1904; além desta família houve registro de Pseudophasmatidae Rehn, 1904, gênero Paraphasma Redtenbacher, 1906. Não foi possível identificar os indivíduos coletados em nível especifico, devido à falta de literatura e as dúvidas quanto à validade da maioria das espécies.

Outra consideração é que espécies aladas geralmente habitam o dossel de vegetações com alturas médias superiores a cinco metros (Conle \& HeNnEMANn 2011), o que pode explicar a baixa riqueza e abundância de espécies aladas (apenas uma). Porém, é válido ressaltar que a metodologia utilizada no presente estudo não é apropriada para captura de espécimes alados, já que não foi utilizado armadilhas de interceptação de vôo, puçá ou armadilha luminosa, que são as mais adequadas para captura desses insetos que geralmente habitam o dossel.

Uma observação importante a ser feita, levando em consideração as morfoespécies encontradas no presente estudo, é que a há grandes possibilidades de serem espécies novas, uma vez que os espécimes coletados apresentam características distintas das espécies já descritas no Brasil e os locais de coleta do presente estudo nunca havia sido amostrada. Outra consideração pertinente às coletas, é que além dos espécimes adultos e das ninfas, foram coletados ovos já eclodidos em área próxima ao Parque Nacional das Sempre Vivas na estação seca. A coleta desse conjunto de ovos contraria a característica padrão observada na postura de ovos da maioria das espécies de fasmídeos, que é feita de forma individual, uma vez que foram encontrados todos juntos sobre uma folha, com um material que os faziam permanecerem grudados uns aos outro. A partir das análises realizadas sob microscópio esteroscópio, foi possível identificar as características básicas de um ovo de Phasmatodea, que é a presença de placa micropilar e opérculo, sendo possível desta forma afirmar que se tratava de ovos de indivíduos da ordem. Como todos os ovos já se encontravam eclodidos não se pode afirmar em que período foram ovipositados ou mesmo quando eclodiram. Esses ovos assemelham-se ao padrão (forma, coloração e tamanho) dos ovos de Paraleptynia.

Trabalhos sobre levantamento faunístico são muito importantes para o conhecimento dos padrões de distribuição das espécies, assim como a sistemática, que pode servir como base para o desenvolvimento de outros trabalhos de outras naturezas, como de ecologia e biogeografia.

Em se tratando da taxonomia da Phasmatodea, conclui-se que a carência de especialistas tem sido um grande empecilho no desenvolvimento e maior conhecimento desta ordem, desta forma é importante ressaltar que a continuidade desse levantamento é de extrema importância, uma vez que a ordem é pouco estudada e conhecida, assim como a fauna de invertebrados da Cadeia do Espinhaço. Dessa forma, pode-se concluir que os dados adquiridos para o conhecimento da ordem no Brasil.

\section{Sistemática}

\section{Família HETERONEMIIDAE Rehn, 1904}

A família Neotropical Heteronemiidae é composta por uma única subfamília Heteronemiinae, que é composta por três tribos, Heteronemiini, Canuleiini (Pygirhynchini) e Paraleptyniini. A tribo Heteronemiini é composta por cinco gêneros Heteronemia Gray, 1835, Minteronemia Zompro, 2004, Splendidonemia Zompro, 2004 e Xeropsis Redtenbacher, 1906. Já Canuleiini é composto por Canuleius Stål, 1875, Ceroys Serville, 1838 e Pygirhynchus Serville, 1838. Por último, a tribo Paraleptyniini é composta por Parabacillus Caudell, 1903, Paraleptynia Caudell, 1904 e Xiphophasma Rehn, 1913. Heteronemiidae é a família que possui o maior número de espécies dentro da ordem (Zoмpro, 2001).

\section{Gênero Heteronemia Gray, 1835}

Diagnose: Indivíduos ápteros, variando de delgados a robustos com ou sem protuberâncias. Cabeça com comprimento maior que o protórax e antenas tão longas quanto a cabeça e o protórax juntos.

Distribuição: Ocorre principalmente na América Central (principalmente Belize, Costa Rica, El Salvador, Guatemala e México) e América do Sul (principalmente Brasil, Chile, Paraguai e Venezuela).

\section{Heteronemia sp. (Figuras 2-10)}

Descrição-Fêmea:Áptera, corpocomespinhoseprotuberâncias visíveis, distribuídos por toda a cabeça, protórax e mesotórax. Coloração marrom. Corpo (Figura 2): 150,40 mm de comprimento e $2,3 \mathrm{~mm}$ de largura (metatórax). Cabeça provida com quatro espinhos distribuídos em pares em sua região dorsal(Figura 3), sendo os anteriores maiores; com 5,43 mm de comprimento e $2 \mathrm{~mm}$ de largura. Antenas longas e filiforme tão longas quanto a perna I. Tórax providos de espinhos, sendo que o mesotórax com dois espinhos maiores que os demais. Protórax: 6,08 mm de comprimento e 2,5 mm de largura; Mesotórax: 31,94 mm de comprimento e 2,6 mm de largura; Metatórax: 21,57 mm de comprimento e 2,3 mm de largura. Pernas: sem protuberâncias; Fêmures I, II e III com 31,28; 24,89 e 31,02 mm de comprimento, respectivamente; Tíbias I, II e III com 31,14; 26,55 e 32,47 mm de comprimento, respectivamente; Tarsos I, II e III com 6,57; 7,22 e $8,42 \mathrm{~mm}$ de comprimento, respectivamente. Abdômen com $70,90 \mathrm{~mm}$ de comprimento e 1,8 $\mathrm{mm}$ de largura. Cercos muito curtos com 1,4 mm de comprimento e placa genital (ovipositor) alongada com 26,08 mm de comprimento (Figura 4).

Macho: Áptero, corpo com espinhos e protuberâncias, principalmente no pro e mesotórax. Coloração marrom. Corpo (Figura 5): 122,87 $\mathrm{mm}$ de comprimento e 1,4mm de largura (metatórax). Cabeça com 3,86 mm de comprimento e 1,2 mm de largura (Figura 6). Antenas longas e filiforme tão longas quanto a perna I. Tórax providos de espinhos; Protórax: 4,16 mm de comprimento e 1,5 mm de largura; Mesotórax: 32,53 mm de comprimento e 1,2 mm de largura; Metatórax: 23,28 mm de comprimento e 1,4 mm de largura. Pernas: sem protuberâncias; Fêmures I, II e III com 33,39; 31,84 e 37,21 mm de comprimento, respectivamente; Tíbias I, II e III com 40,67; 34,97 e 40,91 mm de comprimento, respectivamente; Tarsos I, II e III com 6,97; 7,53 e 8,04 $\mathrm{mm}$ de comprimento, respectivamente. Abdômen com $59,88 \mathrm{~mm}$ de comprimento e $1,2 \mathrm{~mm}$ de largura. Placa subgenital com 18,58 mm de comprimento (Figura 7).

Ovos: Cápsula com superfície de textura lisa, marrom-clara, com manchas irregulares marrom-escuras por toda a cápsula (Figura 8). Comprimento total 3,9 mm de comprimento e 2,9 $\mathrm{mm}$ de largura. Opérculo de cor preta, com retículos que saem da base e se encontram para formar um círculo (Figura 9), com 0,7 de comprimento e 1,9 de largura. Placa micropilar (Figura 10) com o,8 de largura e 3,2 $\mathrm{mm}$ de comprimento.

Comentários: A princípio, os indivíduos de Heteronomia sp. apresentaram dimorfismo sexual, tais como: (i) corpo do macho mais delgado do que da fêmea e com maior quantidade de protuberâncias no tórax; (ii) as protuberâncias torácicas do macho são mais arredondadas, enquanto que na fêmea são mais pontiagudas, assemelhando-se mais a espinhos; (iii) o macho placa subgenital alongada, característica comumente observada somente em fêmeas, o que pode conduzir a erros na sexagem dos espécimes quando utilizar-se desta estrutura. A sexagem nesta espécie só foi possível após a coleta e acompanhamento 
do desenvolvimento pós-embrionários de ninfas. As fêmeas desta espécie assemelha-se com Heteronemia foliata (Brunner von Wattenwyl, 1907), porém a primeira possui o protórax mais arredondado e largo, sendo muito distinto da cabeça o que não acontece em $H$. foliata. Além disso, $H$. foliata possui protuberâncias nos fêmures II inexistentes em Heteronomia sp.

Material examinado: 15 fêmeas, 2 machos e 14 ninfas coletados no Caminho dos Escravos, Diamantina-MG.

\section{Gênero Paraleptynia Caudell, 1904}

Diagnose: Ápteros, com corpo delgado e sem espinhos ou protuberâncias. Cabeça mais longa que o protórax e sem espinhos; antenas filiformes variando de curtas a longas; Fêmeas com placa subgenital (ovipositor) extremamente longa.

Distribuição: Os indivíduos deste gênero possuem distribuição pouco conhecida, sendo que até o presente trabalho, havia registro do gênero apenas em Sapucaí, Paraguai (Brock et al. 2011), e Mato Grosso, Brasil (Conle \& Hennemann 2011).

\section{Paraleptynia sp.1 (Figuras 11-16)}

Descrição-Fêmea: Áptera, corpo delgado com textura lisa sem espinhos e protuberâncias de cor marrom, sendo mais claro na parte dorsal da cabeça e tórax. Corpo (Figura 11): 78,4 $\mathrm{mm}$ de comprimento e 1,7 mm de largura (metatórax). Cabeça sem vértice e tubérculos (Figura 12); duas vezes maior que o pronoto; com $5 \mathrm{~mm}$ de comprimento e $2 \mathrm{~mm}$ de largura. Antenas curtas e filiformes com 19 antenômeros. Tórax: Protórax: 3,1 mm de comprimento e 1,8 mm de largura; Mesotórax: $16 \mathrm{~mm}$ de comprimento e 1,7 mm de largura; Metatórax: 15,6 mm de comprimento e 1,7 mm de largura. Pernas: sem protuberâncias; Fêmures I, II e III com 27; 19 e $24 \mathrm{~mm}$ de comprimento, respectivamente; Tíbias I, II e III com 28; 18,7 e 23,8 mm de comprimento, respectivamente; Tarsos I, II e III com 7,8; 5,o e 6,o mm de comprimento, respectivamente. Abdômen com 38,7 $\mathrm{mm}$ de comprimento e 1,9 $\mathrm{mm}$ de largura. Segmento anal: 2,9 $\mathrm{mm}$ de comprimento e $1,8 \mathrm{~mm}$ de largura. Cercos muito curtos com 1,1 mm de comprimento. Ovipositor alongado (Figura 13), com $21 \mathrm{~mm}$ de comprimento.

Macho: Áptero, corpo delgado com textura lisa sem espinhos e protuberâncias. Coloração inteiramente marrom-escuro. Corpo (Figura 14): 63,2 mm de comprimento e 1,2 $\mathrm{mm}$ de largura (metatórax). Cabeça sem vértice e tubérculos; 3,8 mm de comprimento e $1,5 \mathrm{~mm}$ de largura (Figura 15). Antenas curtas e filiformes com 20 antenômeros. Tórax: Protórax: 2,5 $\mathrm{mm}$ de comprimento e 1,2 $\mathrm{mm}$ de largura; Mesotórax: 13,2 mm de comprimento e 1,1 mm de largura; Metatórax: $12,7 \mathrm{~mm}$ de comprimento e $1,1 \mathrm{~mm}$ de largura. Pernas: sem protuberâncias; Fêmures I, II e III com 25,1; 17,1 e 21,5mm de comprimento, respectivamente; Tíbias I, II e III com 24,8; 16,2; e 19,1 mm de comprimento; Tarsus II, II e III com 7,1; 5,5 e 6,1 mm de comprimento, respectivamente. Abdômen: $31 \mathrm{~mm}$ de comprimento e 1,2 $\mathrm{mm}$ de largura; Segmento anal: $2 \mathrm{~mm}$ de comprimento e 1mm de largura; Cercos muito curtos com 1,1 mm de comprimento (Figura 16).

Comentários: Paraleptynia sp.1 assemelham-se a Paraleptynia catastates (Rehn, 1907), porém esta apresenta uma cabeça mais alongada e delgada e protórax mais distinto da cabeça. Além disso, Paraleptynia sp.1 apresenta coloração uniforme em todo o corpo, enquanto $P$. catastates possui coloração variada, mesclando entre verde e marrom.

Material examinado: 10 indivíduos, sendo 4 fêmeas e 10 machos coletados na mata ciliar do Córrego Soberbo no interior do Campus JK-UFVJM.

\section{Paraleptynia sp.2 (Figuras 17-25)}

Descrição-Fêmea: Áptera, corpo delgado com textura lisa sem espinhos e protuberâncias. Coloração verde claro. Corpo (Figura 17): 75,2 $\mathrm{mm}$ de comprimento e 1,6 mm de largura (metatórax). Cabeça sem vértice e tubérculos, presença de linha branca (Figura 18) que se estende da base da antena (pedicelo) ao pronoto, paralela aos olhos; duas vezes longa que o pronoto, com 5,0 mm de comprimento e $2 \mathrm{~mm}$ de largura. Antenas curtas e filiformes com 20 antenômeros. Tórax: Protórax: 3,0 mm de comprimento e 1,9 mm de largura; Mesotórax: 14,8 mm de comprimento e 1,6 mm de largura; Metatórax: 14,4 mm de comprimento e 1,6 mm de largura. Pernas: sem protuberâncias; Fêmures I, II e III com 25,2; 22,1 e 23,9 mm de comprimento, respectivamente; Tíbias I, II e III com 24,8; 17,5 e 22,1 mm de comprimento, respectivamente; Tarsos I, II e III com 7,2; 4,9 e 5,1 $\mathrm{mm}$ de comprimento, respectivamente. Abdômen com 38,0 $\mathrm{mm}$ de comprimento e 1,9 $\mathrm{mm}$ de largura. Segmento anal: 3,1 $\mathrm{mm}$ de comprimento e $0,9 \mathrm{~mm}$ de largura. Cercos com 1,0 mm de comprimento. Ovipositor alongado (Figura 19), com $20 \mathrm{~mm}$ de comprimento.

Macho: Áptero, corpo como descrito para a fêmea. Coloração marrom. Corpo (Figura 20): 62,6 $\mathrm{mm}$ de comprimento e 1,1mm de largura (metatórax). Cabeça sem vértice e tubérculos, presença de linha branca (Figura 21) que se estende da base da antena (pedicelo) ao pronoto, paralela aos olhos; com 4,1mm de comprimento e $1 \mathrm{~mm}$ de largura. Antenas como na fêmea. Tórax: Protórax: 2,8 mm de comprimento e 1,2 $\mathrm{mm}$ de largura; Mesotórax: 13,0 mm de comprimento e 1,0 mm de largura; Metatórax: 11,7 mm de comprimento e 1,1 mm de largura. Pernas: sem protuberâncias; Fêmures I, II e III com 25,0; 16,2 e 21,2 mm de comprimento, respectivamente; Tíbias I, II e III com 24,0; 17,2 e 22,0 mm de comprimento, respectivamente; Tarsos I, II e III com 7,2; 4,8 e 5,7 mm de comprimento, respectivamente. Abdômen com 31,0 mm de comprimento e 1,0 mm de largura. Segmento anal: 2,1 $\mathrm{mm}$ de comprimento e 1,0 mm de largura.

Ovos: Cápsula com superfície de textura rugosa e porosa, de coloração bege-claro (Figura 23). Comprimento total $5,5 \mathrm{~mm}$ de comprimento e 1,4 $\mathrm{mm}$ de largura. Opérculo da mesma cor da cápsula (Figura 24), comprido e pontiagudo, com 1,1 de comprimento e 1,2 de largura. Placa micropilar (Figura 25) com o,9 de largura e o,8 $\mathrm{mm}$ de comprimento.

Comentários: Paraleptynia sp.2 apresenta um par de linhas brancas na cabeça, que se estende da base da antena ao pronoto. Até o presente trabalho, só houve descrição de duas espécies para o gênero, Paraleptynia fosteri Caudell, 1904 e Paraleptynia catastates (Rehn, 1907), ambas descritas a partir de coletas no Paraguai, e um registro em Mato Grosso, Brasil, na qual a espécie ainda não fora identificada (Conle \& Hennemann 2011). As espécies aqui estudadas distingue-se daquela registrada em Mato Grosso a cápsula dos ovos mais irregulares, com aspecto mais rugoso e com a placa micropilar mais profunda.

Material examinado: 14 indivíduos, sendo sete fêmeas e sete machos coletados na mata ciliar do Córrego Soberbo no interior do Campus JK-UFVJM.

\section{Família PSEUDOPHASMATIDAE Rehn, 1904}

Pseudophasmatidae apresenta três subfamílias, Pseudophasmatinae, composta por duas tribos, Pseudophasmatini com os sete gêneros e Anisomorphini com oito gêneros; Xerosomatinae, composta por três tribos, sendo elas Prexaspini, com 10 gêneros, Xerosomatini com nove gêneros e Setosini com apenas um gênero, e a Stratocleinae, que contém 16 gêneros conhecidos na América Central e do Sul. Este táxon é representado por espécies aladas capazes de habitar o dossel de floretas tropicais, sendo Paraphasma e Stratocles os mais comuns na América do Sul. A maior diversidade do táxon é encontrada no nordeste da América do Sul, como a Colômbia. 
Gênero Paraphasma Redtenbacher, 1906

Diagnose: Alados, com as asas anteriores extremamente curtas quando comparadas às posteriores; asas posteriores longas cobrindo praticamente todo o abdômen. Antenas longas, maiores que o comprimento do corpo.

Distribuição: Ocorre principalmente na América Central, América do Sul (Bolívia, Brasil, Equador, Paraguai, Peru e Suriname) e Indo-Malásia.

\section{Paraphasma sp. (Figuras 26-28)}

Descrição- Macho: Coloração castanho-escuro, com algumas manchas irregulares castanho-claras na cabeça, pronoto e mesonoto. Asas anteriores com manchas avermelhadas e as posteriores castanho-alaranjada. Corpo (Figura 26): 50,90 mm de comprimento e 1,2mm de largura (metatórax). Cabeça sem vértice e tubérculos (Figura 27) com $2.61 \mathrm{~mm}$ de comprimento e $1,3 \mathrm{~mm}$ de largura. Antenas longas e filiforme, com aproximadamente 55,40 mm de comprimento. Tórax: Protórax: 2,68 mm de comprimento e 1,3 mm de largura; Mesotórax: 5,26 mm de comprimento e 1,2 mm de largura; Metatórax: 6.27 mm de comprimento e 1,3 mm de largura. Pernas: sem protuberâncias; Fêmures I, II e III com 12,77; 8,82 e 11,36 mm de comprimento, respectivamente; Tíbias I, II e III com 12,78; 7,26 e 6,65 mm de comprimento, respectivamente; Tarsos I, II e III com 6,65; 5,02 e 6,44 $\mathrm{mm}$ de comprimento, respectivamente. Abdômen com $30,71 \mathrm{~mm}$ de comprimento e 1,1 mm de largura (Figura 28). Asas Anteriores com 3.68mm de comprimento e posteriores com 31,15 mm de comprimento.

Comentários: Paraphasma sp. assemelha-se a Paraphasma maculatum (Gray, 1835) e Paraphasma quadratum (Bates, 1865) pelo comprimento das asas, tamanho e espessura corporal. No entanto, diferencia-se pela coloração do corpo, que em $P$. maculatum é mais clara e com mais manchas por toda cabeça e abdômen e em $P$. quadartum é mais escura. Além disso, as asas anteriores de Paraphasma sp. apresenta mancha avermelhada, o que não ocorre nas demais espécies e a asa posterior é mais alaranjada que as demais.

Material examinado: 1 indivíduo macho coletado no Parque Estadual do Biribiri.

\section{CHAVE DE IDENTIFICAÇÃO}

A presente chave relaciona as subordens, famílias e gêneros abordados no presente estudo, além dos gêneros Otocraniella Zompro, 2004 e Cladomorphus Gray, 1835 que possuem espécies coletadas e descritas no Estado de Minas Gerais.

1 - Tíbia com Área Apical

EUPHASMATODEA “AREOLATAE”: 2

1'- Tíbia sem Área Apical EUPHASMATODEA “ANAREOLATAE”: PHASMATIDAE: 4

2 - Insetos ápteros; fêmur com três pontas, arestas lameladas.

HETERONEMIIDAE: 3

2' - Insetos ápteros ou alados; quando alados o par de asas anterior são curtas e as asas posteriores cobre praticamente todo o abdômen; apresentam manchas irregulares por toda a cabeça e tórax (Figura 26)... PSEUDOPHASMATIDAE: Paraphasma

3- Corpo robusto coberto de espinhos ou delgado com ou sem espinhos, cabeça maior que o protórax; antenas geralmente longas (Figuras 2 e 5 Heteronemia

3'- Corpo delgado sem espinhos, antenas geralmente curtas, menores do que o par de pernas I; placa subgenital extremamente alongada na fêmea (Figura 11) Paraleptynia

4 - Fêmeas ápteras e machos alados; corpo com textura rugosa com presença de espinhos; placa subgenital curta na fêmea

..Cladomorphus

4'- Corpo delgado. Cabeça com vários tubérculos pequenos. Antenas longas e relativamente grossas. Meso e metatórax fortemente granulosos e com espinhos. Segmento mediano maior do que o metatórax. Placa subgenital fortemente alongada...........Otocraniella

\section{AGRADECIMENTOS}

À FAPEMIG pela bolsa de Iniciação Científica para a primeira autora. Aos professores José Paulo Leite Guadanucci e Sebastião Lourenço de Assis Junior pelas críticas nas primeiras versões do manuscrito e a dois revisores pelas sugestões que enriqueceram muito este trabalho. A Filipe Moura pelo auxílio nas coletas do material biológico, Oskar Conle por confirmar as identificações aqui efetuadas e Anete Lourenço e Thiago Araujo na montagem do mapa com os pontos de coleta.

\section{REFERÊNCIAS}

Almeida-Abreu, P.A., L.M.S. Fraga \& S.C. Neves, 2005. Geologia, p. 17-44. In: Silva, A.C., Fortes, L.C.V.S. \& Almeida-Abreu, P.A. Serra do Espinhaço Meridional: paisagens e ambientes. Ed. O Lutador, 272p.

Azevedo, A.A., R.L. Fonseca \& R.B. Machado, 2008. Cadeia do Espinhaço: avaliação do conhecimento científico e prioridade de conservação. Megadiversidade, 4: 3-4.

Bedford, G.O., 1978. Biology and Ecology of the Phasmatodea. Annual Review of Entomology, 23:125-49.

Brock, P.D \& J.W. Hasenpush, 2009. The complete field guide to stick and leaf insects of Australia. Ed. Csiro Publishing, 204p.

Brock, P.D., D.C. Eades, D. Otte \& E. Baker, 2011. Phasmida Species File Online (Version 2.1/4.0). Disponível em http://phasmida.speciesfile.org/HomePage.aspx. Acesso em 01/Jun/ 2011.

Conle, O. \& F.H. Hennemann, 2011. Classification of Phasmatodea. Disponível em http://www.phasmatodea.com/web/guest/classification. Acesso em: 11/Jun/2011.

Costa-Lima, A.M., 1938. Insetos do Brasil. 10 Tomo. Escola Nacional de Agronomia, Série Didática N. ${ }^{\circ}$ 2. 468p.

Nel, A., F. Marchal-Papier, O. Béthoux \& J. C. Gall, 2004. A "stick insect-like" from the Triassic of the Vosges (France) ("pre-Tertiary Phasmatodea"). Annales de La Societe Entomologique de France, 40: 31-36.

Oliveira, C.M. \& M.R. Frizzas, 2008. Insetos de Cerrado: distribuição estacional e abundância. Boletim de Pesquisa e Desenvolvimento, EMBRAPA, 216: 1-26.

Otte, D. \& P. Brock, 2005. Phasmida species file: catalog of stick and leaf insects of the world. Philadelphia, Insect Diversity Association at the Academy of Natural Sciences, 296p.

Tilgner, E.H., 2002. Systematics of Phasmida. Tese de Doutorado. University of Georgia, 119p.

Zompro, O., 2001. Redescription and new Synonymies of 
Heteronemia Gray, 1835 (Insecta: Phasmatodea) Transferred to the suborder Areolatae. Studies on Neotropical Fauna and Environment, 35: 221-225.

Zompro, O., 2004. Revision of the genera of the Areolatae, including the status of Timema and Agathemera (Insecta: Phasmatodea). Abhandiungen des Naturwissenschaftlichen Vereins in Hamburg, 37: 1-327.

Zompro, O. \& F.C. Domenico, 2005. Catalogue of the type material of Phasmatodea (Insecta) depositedin Brazilian Museums. Iheringia, 95: 255-259.

\section{Recebido em: 24/o1/2012 \\ Aceito em: 05/06/2012}
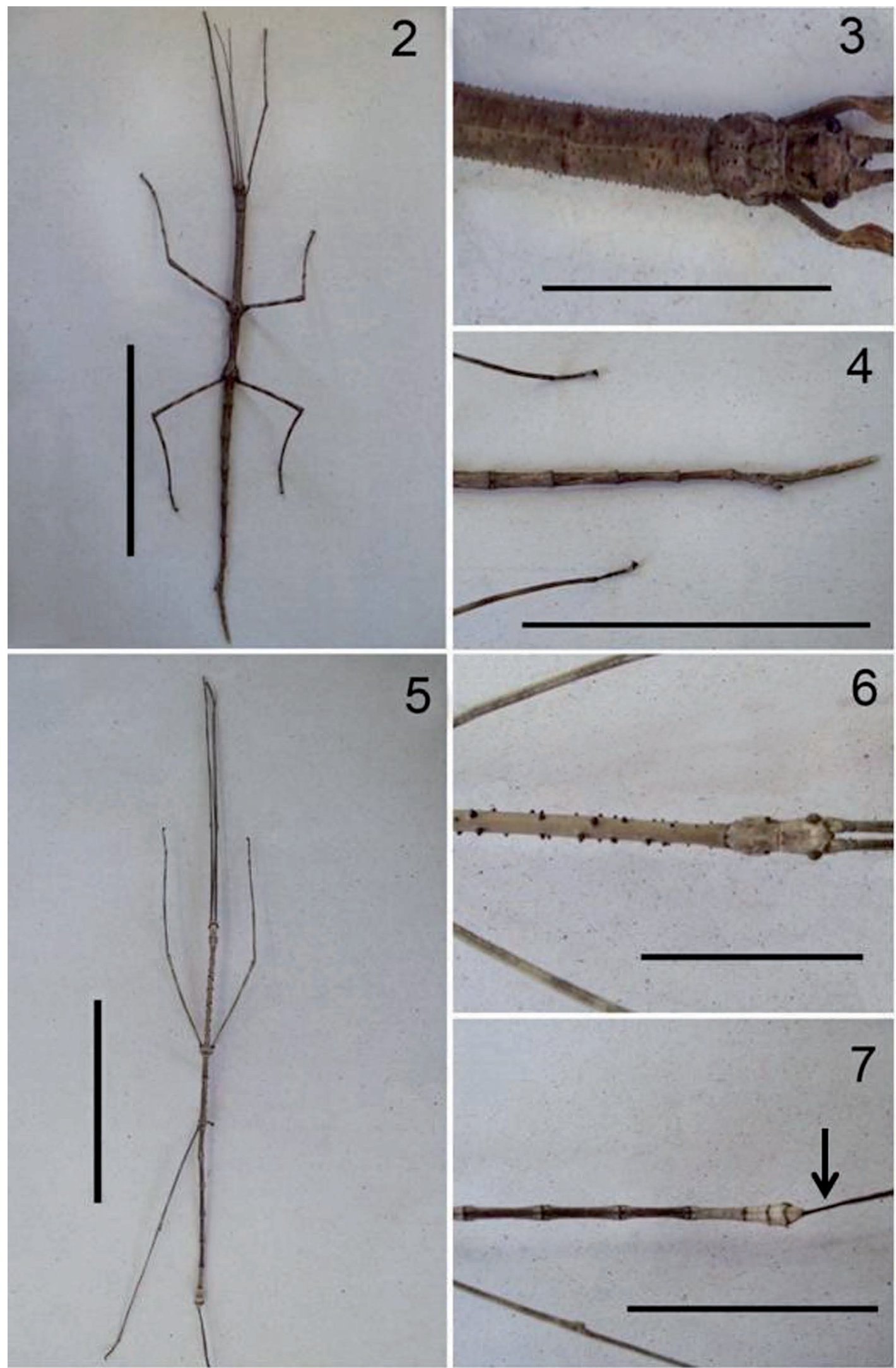

Figuras 2-7: Heteronemia sp. Fêmea. 2- Vista dorsal do indivíduo adulto (Escala 8omm); 3- Vista dorsal da cabeça, protórax e metatórax (Escala 25mm); 4- Vista dorsal de parte do abdômen e ovipositor (Escala 35mm). Macho. 5- Vista dorsal do indivíduo adulto (Escala 6omm); 6- Vista dorsal da cabeça, protórax e metatórax (Escala 10mm); 7- Vista dorsal de parte do abdômen e placa subgenital (Escala 20mm). Sete indica a posição da placa subgential. 


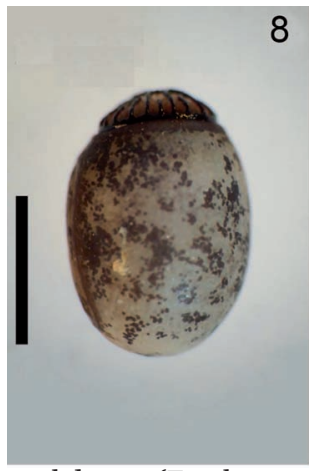

8
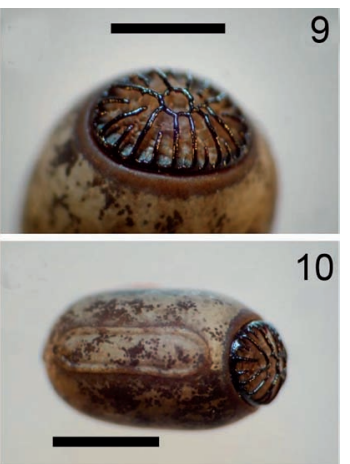

Figuras 8-10: Ovo Heteronemia sp.; 8- Vista frontal do ovo (Escala $2 \mathrm{~mm}$ ); 9- Vista do opérculo (Escala $1 \mathrm{~mm}$ ); 10- Vista frontal da placa micropilar (Escala 1,5 mm).
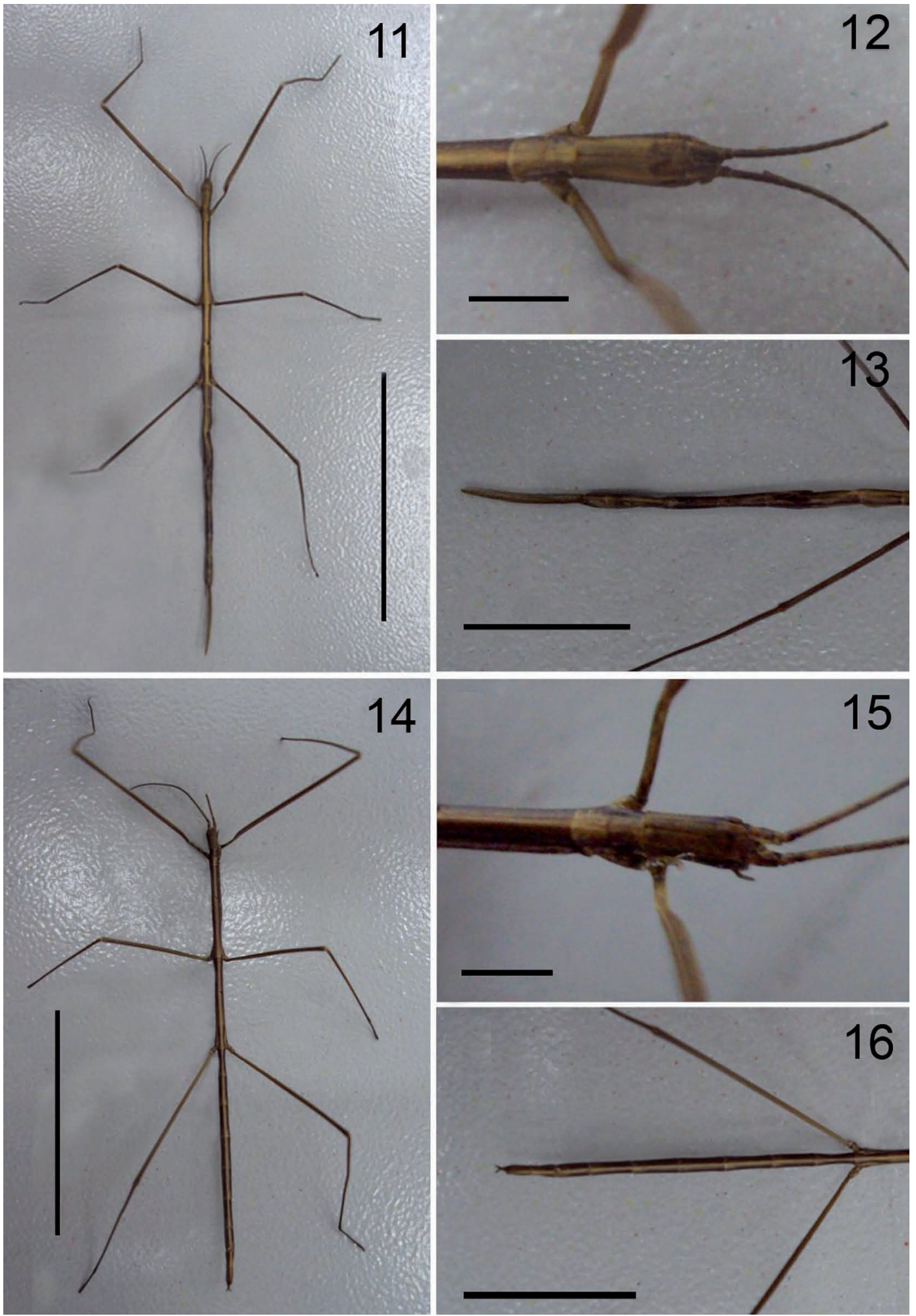

Figuras 11-16: Paraleptynia sp.1 Fêmea. 11-Vista dorsal do indivíduo adulto (Escala $40 \mathrm{~mm}$ ); 12- Vista dorsal da cabeça (Escala 4mm); 13- Vista dorsal de parte do abdômen e ovipositor (Escala 20mm). Paraleptynia sp.1 Macho. 14- Vista dorsal do indivíduo adulto (Esacala 30mm); 15- Vista dorsal da cabeça (Escala 3mm); 16- Vista dorsal do abdômen (Escala 15mm). 

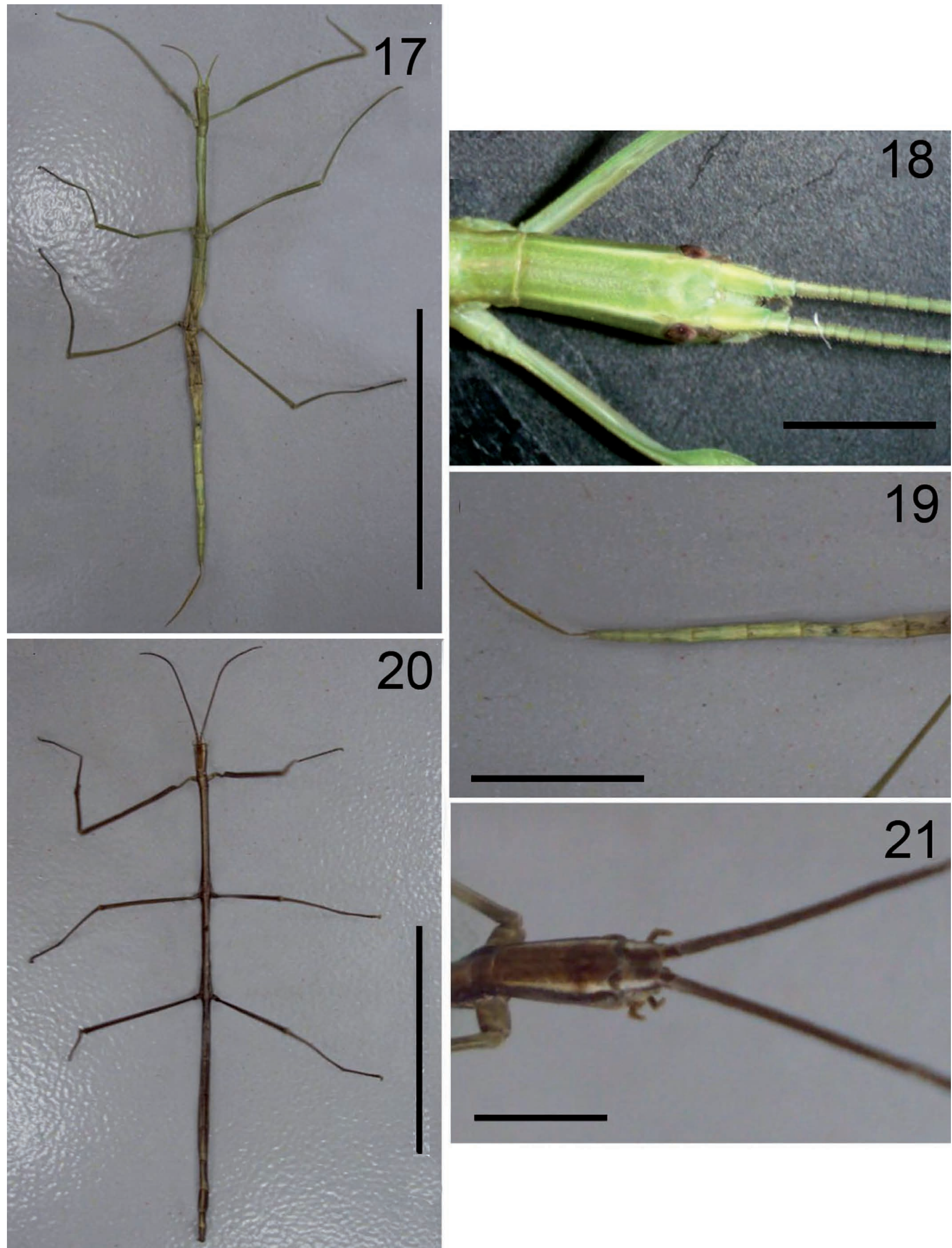

Figuras 17-22: Paraleptynia sp.2 Fêmea. 17- Vista dorsal do indivíduo adulto (Escala 40mm); 18- Vista dorsal da cabeça (Escala 4mm); 19- Vista dorsal de parte do abdômen e ovipositor (Escala 20mm). Paraleptynia sp.2 Macho. 20- Vista dorsal do indivíduo adulto (Escala 30mm); 21- Vista dorsal da cabeça (Escala 2mm); 22- Vista dorsal de parte do abdômen (Escala 10mm). 

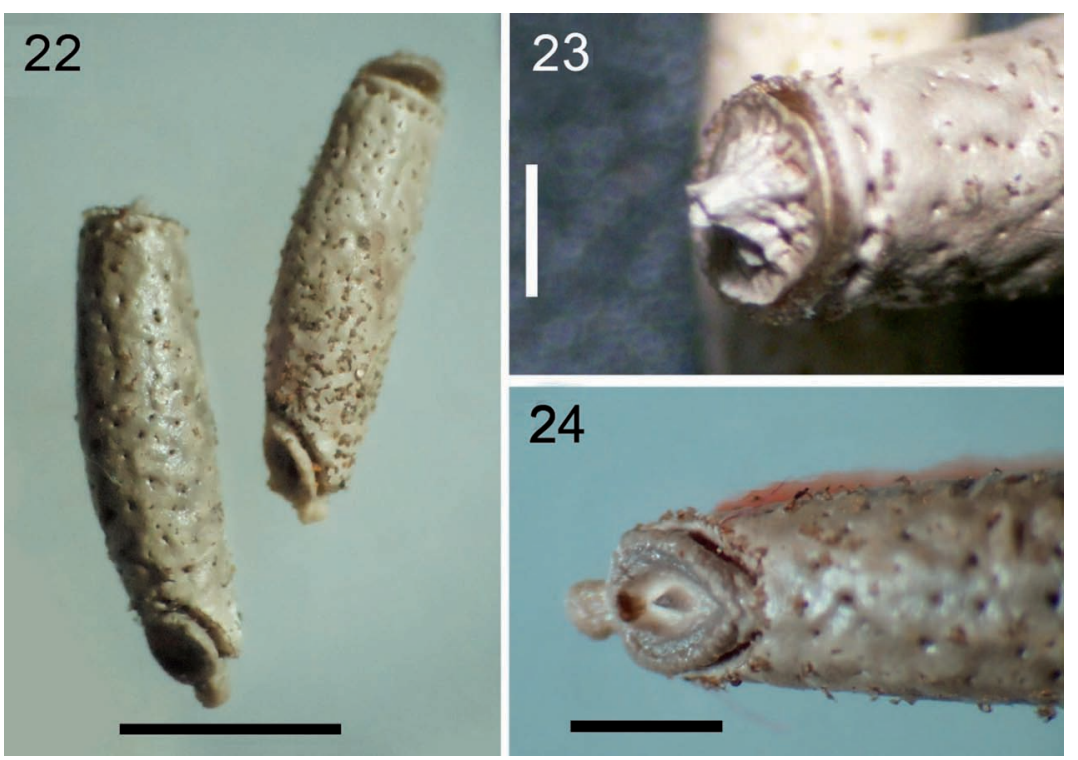

Figuras 23-25: Ovo de Paraleptynia sp.2; 23- Vista lateral do ovo de Paraleptynia sp.2 (Escala 2,5mm); 24- Opérculo de Paraleptynia sp.2 (Escala 1 $\mathrm{mm}$ ); 25- Vista frontal da placa micropilar (Escala $0,5 \mathrm{~mm}$ ).

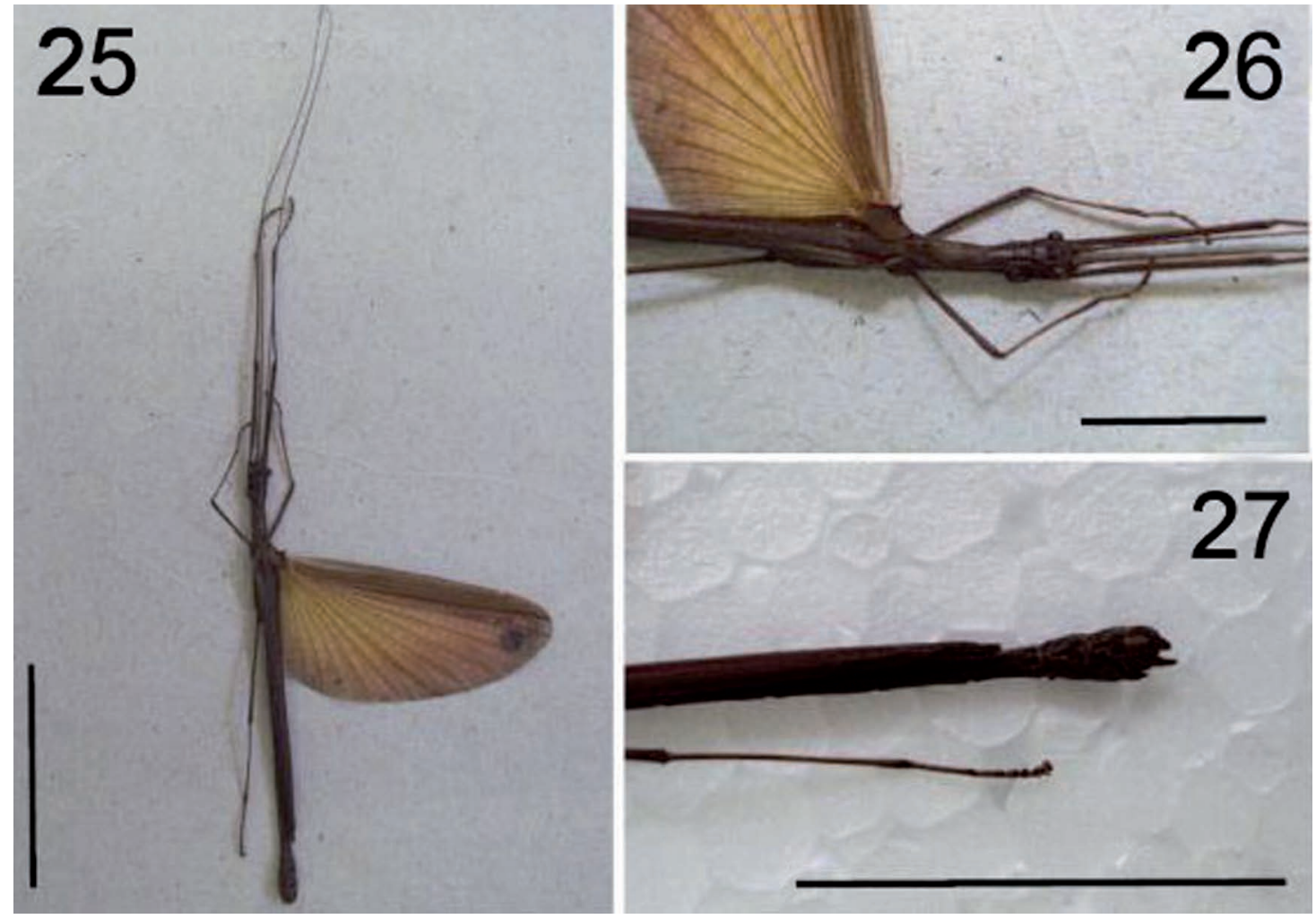

Figuras 26-28: Paraphasma sp. Macho. 26- Vista dorsal do indivíduo adulto (Escala 30mm); 27- Vista dorsal da cabeça, tórax e asas (Escala 15mm); 28- Vista dorsal de parte do abdômen (Escala 15mm).

Como citar este artigo:

Araujo, F.F. \& A.R.S. Garraffoni, 2012. Phasmatodea (Insecta) da Serra do Espinhaço, Chapada Diamantina (MG). EntomoBrasilis, 5(2): 137-145. Acessível em: http://www.periodico.ebras.bio.br/ojs/index.php/ebras/article/view/228

\section{(c) $(1) \odot$}

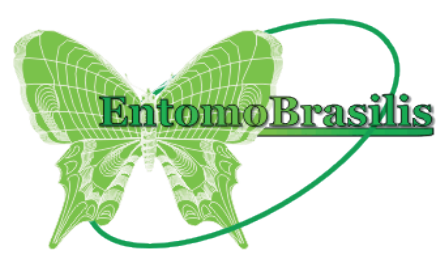

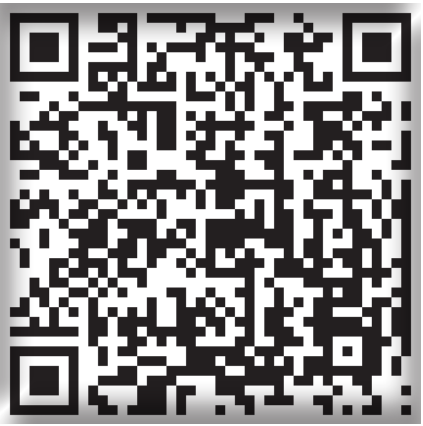

e-ISSN 1983-0572 